\title{
FH535 suppresses the proliferation and motility of hepatocellular carcinoma cells
}

\author{
MINORU TOMIZAWA ${ }^{1}$, FUMINOBU SHINOZAKI ${ }^{2}$, YASUFUMI MOTOYOSHI ${ }^{3}$, \\ TAKAO SUGIYAMA $^{4}$, SHIGENORI YAMAMOTO ${ }^{5}$ and NAOKI ISHIGE ${ }^{6}$ \\ Departments of ${ }^{1}$ Gastroenterology, ${ }^{2}$ Radiology, ${ }^{3}$ Neurology, ${ }^{4}$ Rheumatology, ${ }^{5}$ Pediatrics and ${ }^{6}$ Neurosurgery, \\ National Hospital Organization, Shimoshizu Hospital, Yotsukaido, Chiba 284-0003, Japan
}

Received August 28, 2015; Accepted October 9, 2015

DOI: 10.3892/ijo.2015.3220

\begin{abstract}
The Wnt signaling pathway is activated in hepatocellular carcinoma (HCC). This study investigated the effects of FH535, an inhibitor of the Wnt signaling pathway, on the proliferation and motility of HCC cells. HLF cells and PLC/ $\mathrm{PRF} / 5$ cells, HCC cells, were subjected to 3-(4,5-dimethylthiazol-2-yl)-5-(3-carboxymethoxyphenyl)-2-(4-sulfophenyl)2H-tetrazolium, inner salt (MTS) assay with the addition of FH535. RNA was isolated from the cells and subjected to real-time quantitative PCR. Hematoxylin and eosin (H\&E) staining was performed to analyze apoptosis. A scratch assay was performed to analyze cell motility. Cell proliferation significantly decreased $(\mathrm{P}<0.05)$. The expression levels of cyclin D1 significantly decreased in both cell lines $(\mathrm{P}<0.05)$. Pyknotic nuclei were observed in the cells cultured with FH535 $(50 \mu \mathrm{M})$. In the scratch assay, the distance between the growing edges of cells and the scratched line significantly decreased with the addition of FH535 at $50 \mu \mathrm{M}(\mathrm{P}<0.05)$. The expression levels of matrix metalloproteinase 9 significantly decreased at $50 \mu \mathrm{M}(\mathrm{P}<0.05)$. FH535 suppressed the proliferation of HCC cells by downregulating the expression of cyclin D1 and by inducing apoptosis. Further, it suppressed cell motility by downregulating the expression of matrix metalloproteinase.
\end{abstract}

\section{Introduction}

Hepatocellular carcinoma (HCC) is a cancer originating from the liver. Its prognosis is poor despite the advancements in treatment (1). Treatments for HCC include local ablation, surgery, transcatheter arterial chemoembolization, and chemotherapy $(2,3)$. Molecular therapy has also been established as a treatment option (4). To develop a new molecular therapy, research has focused on signaling pathways (5).

Correspondence to: Dr Minoru Tomizawa, Department of Gastroenterology, National Hospital Organization, Shimoshizu Hospital, 934-5 Shikawatashi, Yotsukaido, Chiba 284-0003, Japan

E-mail: nihminor-cib@umin.ac.jp

Key words: cyclin D1, apoptosis, MTS assay, scratch assay, matrix metalloproteinase 9
The Wnt pathway is involved in cell proliferation and differentiation (6). Wnt proteins bind to their receptor, frizzled, and its co-receptors, low-density lipoprotein receptor-related proteins 5 and 6 (LRP5/6), to form a complex $(7,8)$. $\beta$-catenin is degraded by the glycogen synthase kinase- $3 \beta$ complex (9). When Wnt binds to its receptor complex, the degradation of $\beta$-catenin is inhibited. $\beta$-catenin then accumulates in the cytoplasm and the Wnt pathway is activated. $\beta$-catenin is a co-factor of the T-cell factor (TCF)/lymphoid enhancer factor (LEF). When the Wnt pathway is activated, the accumulated $\beta$-catenin translocates to the nucleus, binds the promoter of target genes with TCF/LEF (10). In HCC, $\beta$-catenin is mutated and overexpressed, which suggests that the Wnt pathway is constitutively activated (11). Therefore, $\beta$-catenin is a potential target in the exploration of molecular therapy (12). The inhibition of frizzled-9 suppresses the proliferation and motility of HCC cells (13). Niclosamide is a drug used for the treatment of tapeworm infections. It is an inhibitor of the Wnt signaling pathway and it suppresses the proliferation of HCC cells (14). Previous reports indicate that the Wnt pathway is a promising target in the treatment of HCC.

FH535 is a small molecule that inhibits the Wnt signaling pathway and peroxisome proliferator-activator receptor signaling (15). One of its unique characteristics is that it inhibits the recruitment of $\beta$-catenin. Therefore, FH535 is expected to be a potent inhibitor of the Wnt signaling pathway.

In this study, we investigated the effects of FH535 on motility and proliferation of HCC cells.

\section{Materials and methods}

Cell culture. HLF cells and PLC/PRF/5 cells, human HCC cells, were obtained from RIKEN Cell Bank (Tsukuba, Japan) and cultured in Dulbecco's modified Eagle's medium (DMEM; Sigma-Aldrich, St. Louis, MO, USA) supplemented with 10\% fetal bovine serum (FBS; Life Technologies, Grand Island, NY, USA). They were cultured in 10-cm dishes (Asahi Techno Glass, Funabashi, Japan) with 5\% carbon dioxide at $37^{\circ} \mathrm{C}$ in a humidified chamber.

Cell proliferation assay. Cells were trypsinized, harvested, and spread onto 96-well plates (Asahi Techno Glass) at a density of 1,000 cells/well. They were cultured in DMEM 
Table I. The primer sequences.

\begin{tabular}{|c|c|c|c|c|c|c|}
\hline $\begin{array}{l}\text { Primer } \\
\text { name }\end{array}$ & Sequence & Description & $\begin{array}{l}\text { Product } \\
\text { size (bp) }\end{array}$ & $\begin{array}{l}\text { Annealing } \\
\text { temperature }\end{array}$ & Cycle & GenBank \\
\hline OMC355 & 5'-AGAGGCGGAGGAGAACAAACAG-3' & Cyclin D1, forward & 180 & 60 & 40 & NM_053056 \\
\hline OMC356 & 5'-AGGCGGTAGTAGGACAGGAAGTTG-3' & Cyclin D1, reverse & & & & \\
\hline OMC749 & 5'-CCTGGGCAGATTCCAAACCT-3' & MMP9, forward & 89 & 60 & 40 & NM_004994 \\
\hline OMC750 & 5'-GCAAGTCTTCCGAGTAGTTTTGGAT-3' & MMP9, reverse & & & & \\
\hline OMC321 & 5'-CGAATGCCAGAGAAGGTCAC-3' & RPL19, forward & 157 & 60 & 40 & BC095445 \\
\hline OMC322 & 5'-CCATGAGAATCCGCTTGTTT-3' & RPL19, reverse & & & & \\
\hline
\end{tabular}

MMP9, matrix metalloproteinase 9; RPL19, ribosomal protein L (RPL) 19.

supplemented with $10 \%$ FBS. The cells were cultured for $72 \mathrm{~h}$ with $0,0.5,1.5,5,15$ or $50 \mu \mathrm{M}$ FH535 (Merck, Darmstadt, Germany) and subjected to 3-(4,5-dimethylthiazol-2-yl)5-(3-carboxymethoxyphenyl)-2-(4-sulfophenyl)-2H-tetrazolium, inner salt (MTS) assay, according to the manufacturer's instructions (Promega Corp., Madison, WI, USA). MTS is reduced by cells to a colored formazan product that has an absorbance maximum at $490 \mathrm{~nm}$. Absorbance was measured using an iMark Microplate Absorbance Reader (Bio-Rad, Hercules, CA, USA).

Real-time quantitative polymerase chain reaction. Total RNA $(5 \mu \mathrm{g})$, which was isolated using Isogen (Nippon Gene, Tokyo, Japan), was used for the first-strand cDNA synthesis with SuperScript III and oligo(dT) following the manufacturer's instructions (Life Technologies). Real-time quantitative PCR was performed using Fast SYBR Green Master Mix (Life Technologies) with MiniOpticon (Bio-Rad). The results were analyzed using the MiniOpticon system. Real-time quantitative PCR was performed for 40 cycles, with $5 \mathrm{sec}$ of denaturation and $5 \mathrm{sec}$ of annealing/extension. The primer sequences are listed in Table I. RPL19 was used as an internal control as the target gene is a constitutively expressed housekeeping gene (16).

Scratch assay and hematoxylin and eosin staining. Cells were plated on 4-well chamber slides (Becton-Dickinson, Franklin Lakes, NJ, USA). When the cells reached confluence, they were scratched with a sterile razor. The cells were incubated with 0 or $50 \mu \mathrm{M}$ FH535 for $48 \mathrm{~h}$ and stained with hematoxylin and eosin (H\&E). For the analysis of apoptosis, the cells were plated in 4-well chamber slides (Becton-Dickinson). The cells were incubated with 0 or $50 \mu \mathrm{M}$ FH535 for $48 \mathrm{~h}$ and then stained with H\&E. The stained slides were observed under an AX80 microscope (Olympus, Tokyo, Japan) for the apoptosis analysis and scratch assay. In the scratch assay, the distance between the scratched line and the growing edges of the cells was measured at five points.

Statistical analysis. Data were analyzed by one-way analysis of variance (ANOVA) using JMP 10.0.2 software (SAS Institute, Cary, NC, USA). P-values $<0.05$ were considered statistically significant.
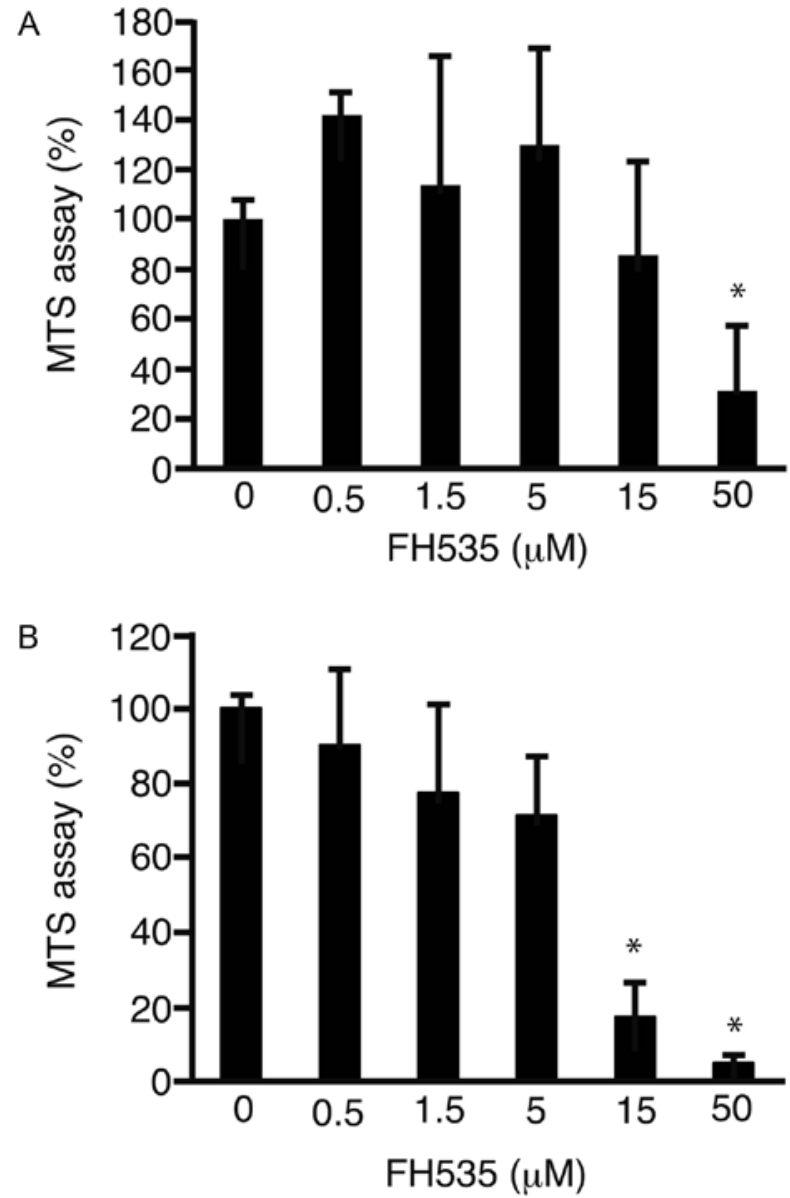

Figure 1. Cell proliferation assay. Cell proliferation was analyzed with HLF cells (A) and PLC/PRF/5 cells (B) cultured in 96-well plates. The cells were incubated with FH535 $(0,0.5,1.5,5,15$, or $50 \mu \mathrm{M})$ and were subjected to MTS assay. Error bar, standard deviation; "P $<0.05$ as compared with $0 \mu \mathrm{M}$, $\mathrm{n}=3$.

\section{Results}

To analyze the suppression of cell proliferation, HLF cells (Fig. 1A) and PLC/PRF/5 cells (Fig. 1B) were cultured with FH535. After $72 \mathrm{~h}$, the cells were subjected to MTS assay. Proliferation was found to be significantly suppressed in both cell lines $(\mathrm{P}<0.05)$. 

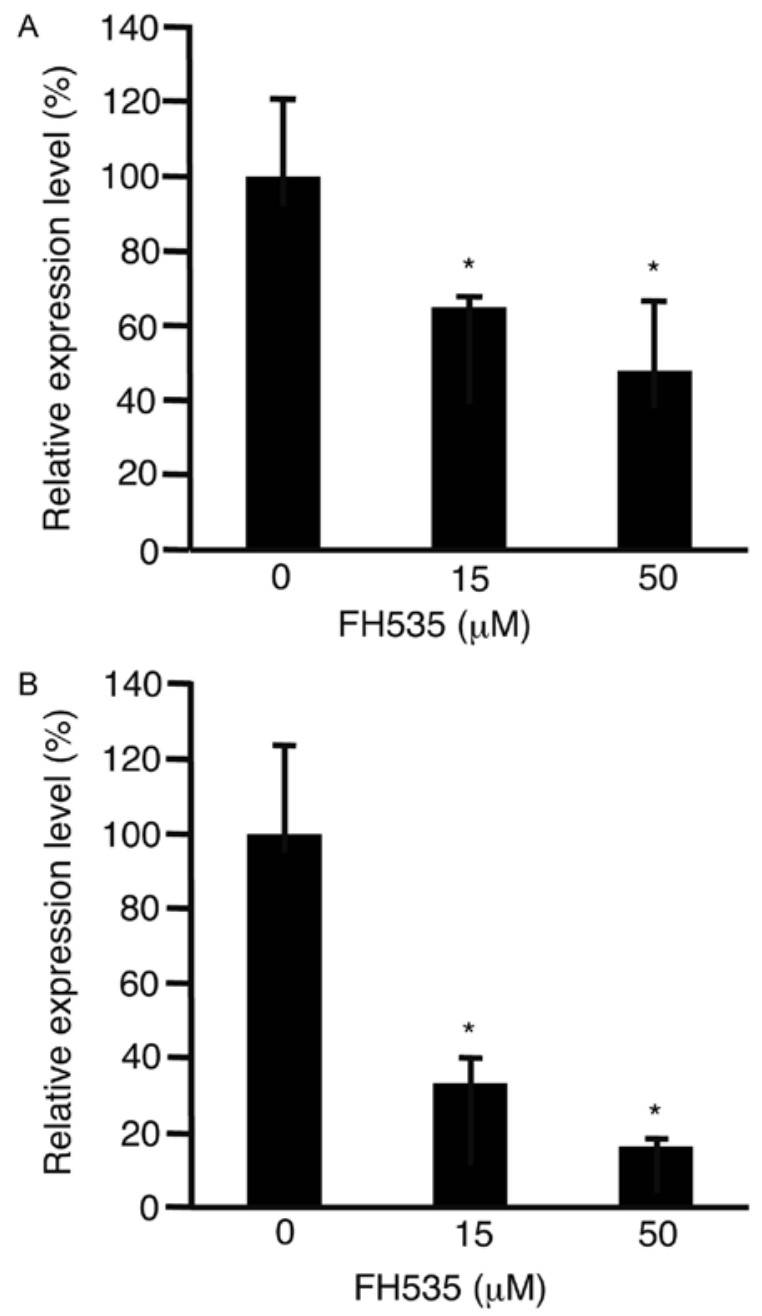

Figure 2. Expression levels of cyclin D1. RNA was isolated from HLF cells (A) and PLC/PRF/5 cells (B), $48 \mathrm{~h}$ after the addition of FH535 at 0 or $50 \mu \mathrm{M}$. The RNA was subjected to real-time quantitative PCR. Error bar, standard deviation; ${ }^{*} \mathrm{P}<0.05$ as compared with $0 \mu \mathrm{M}, \mathrm{n}=3$.

Cylin D1 is involved in the regulation of cell cycle progression (17). To evaluate the expression levels of cyclin D1, HLF cells (Fig. 2A) and PLC/PRF/5 cells (Fig. 2B) were incubated with FH535. After $48 \mathrm{~h}$, RNA was isolated from the cells and subjected to real-time quantitative PCR. The expression levels of cyclin D1 were significantly suppressed in both cell lines $(\mathrm{P}<0.05)$.

To clarify the involvement of apoptosis in the suppression of cell proliferation, HLF (Fig. 3A and B) and PLC/PRF/5 cells (Fig. 3C and D) were incubated with FH535 at $0 \mu \mathrm{M}$ (Fig. 3A and C) or $50 \mu \mathrm{M}$ (Fig. 3B and D) and subjected to H\&E staining. Pyknotic nuclei (arrows) were observed in the cells cultured with $50 \mu \mathrm{M}$ FH535. These results indicate that the cells underwent apoptosis with FH535 at $50 \mu \mathrm{M}$.

To address the possibility that FH535 suppressed cell motility, HLF cells (Fig. 4A and C) and PLC/PRF/5 cells (Fig. 4B and D) were cultured with FH535 at $0 \mu \mathrm{M}$ (Fig. 4A and C) or $50 \mu \mathrm{M}$ (Fig. 4B and D). The distance between the growing edges of the cells and the scratched line significantly decreased with the addition of $50 \mu \mathrm{M}$ FH535 (Fig. 4E) $(\mathrm{P}<0.05)$.

The expression levels of matrix metalloproteinase 9 were analyzed because this gene is involved in cancer metastasis (18). The expression levels of matrix metalloproteinase 9 were significantly suppressed in the HLF cells (Fig. 5A) and PLC/ $\mathrm{PRF} / 5$ cells (Fig. 5B) $(\mathrm{P}<0.05)$.

\section{Discussion}

FH535 suppresses the proliferation of cancer cells. Specifically, in this study, it was observed to suppress the proliferation of HLF cells and PLC/PRF/5 cells. The expression levels of cyclin D1 decreased in both cell types after incubation with FH535. In the HCC cells, FH535 decreased the expression levels of cyclin D1 and suppressed the cell cycle (19). These

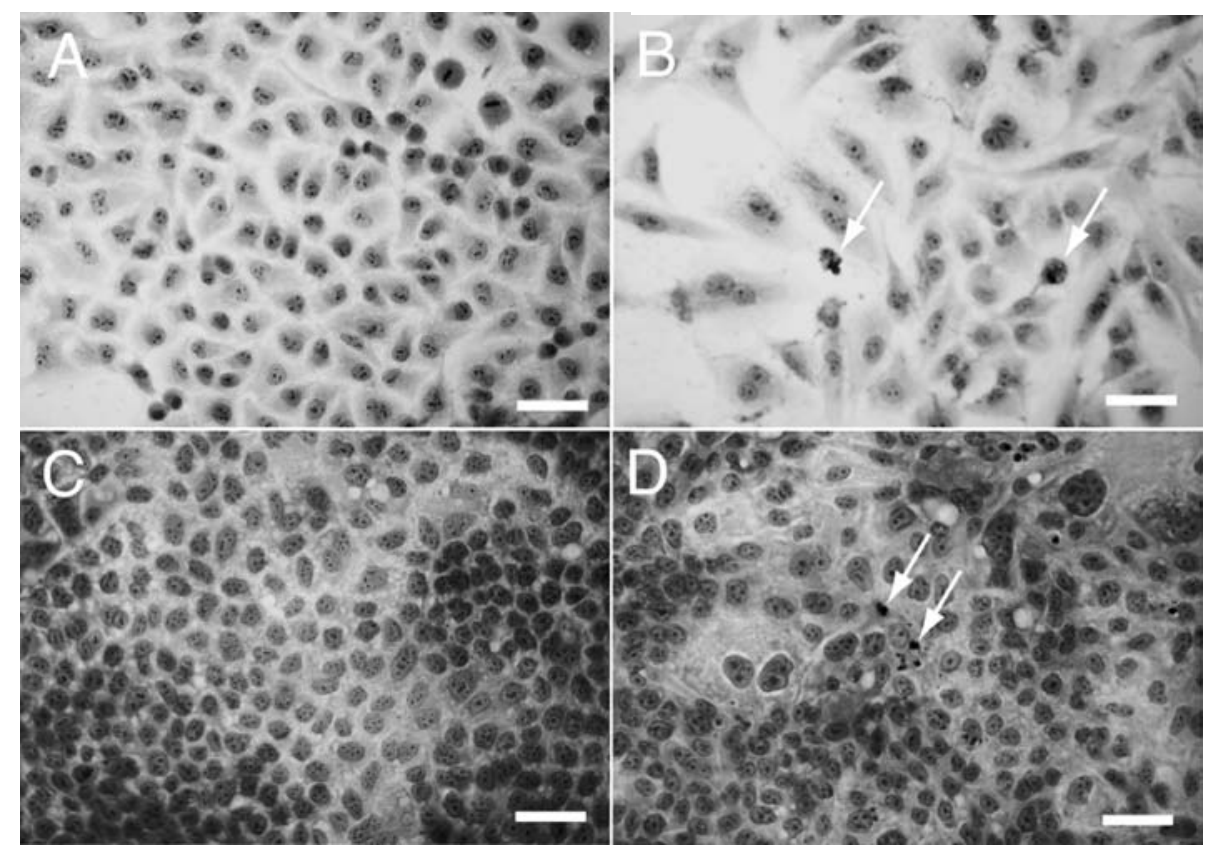

Figure 3. Hematoxylin and eosin staining. HLF cells (A and B) and PLC/PRF/5 cells (C and D) were cultured with FH535 [0 $\mu \mathrm{M}$ (A and C) or $50 \mu \mathrm{M}$ (B and D)] for $48 \mathrm{~h}$ and subjected to hematoxylin and eosin staining. Pyknotic nuclei were observed (arrows). Original magnification, $\mathrm{x} 400 ; \mathrm{scale}$ bar, $50 \mu \mathrm{m}$. 

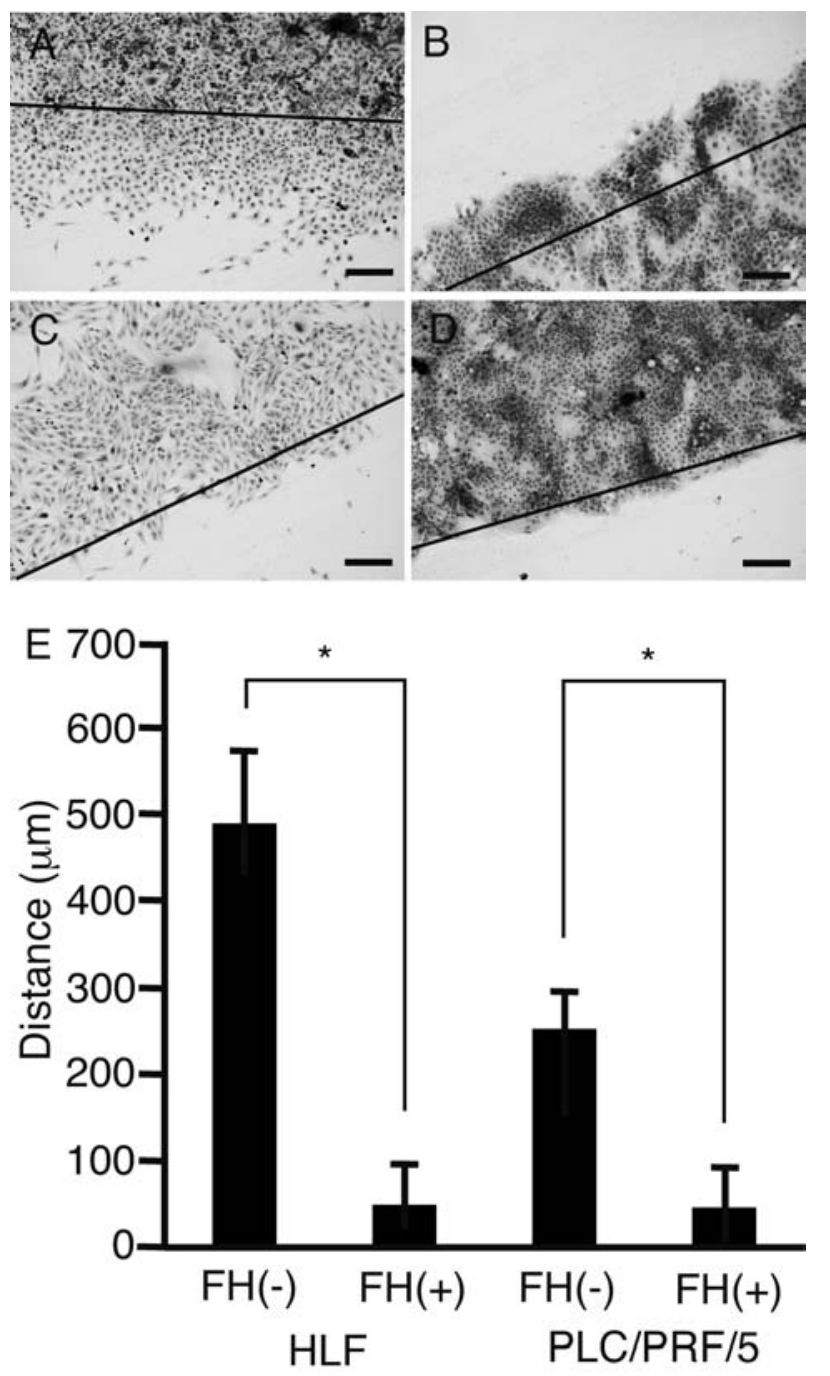

Figure 4. Scratch assay. The cell sheets of HLF cells (A and C) and PLC/PRF/5 cells (B and D) were scratched with a sterile razor, cultured with FH535 at $0 \mu \mathrm{M}[\mathrm{FH}(-)]$ or $50 \mu \mathrm{M}[\mathrm{FH}(+)]$ for $48 \mathrm{~h}$, and subjected to hematoxylin and eosin staining. The distance between the growing edges of the cells and the scratched line (solid line) was measured at five points (E). Original magnification, x100; scale bar, $200 \mu \mathrm{m}$; error bar, standard deviation; " $\mathrm{P}<0.05$ as compared with $\mathrm{FH}(-), \mathrm{n}=3$.

results were consistent with those of the previous reports. The data clearly showed that the cells underwent apoptosis. The results indicated that FH535 suppressed cell proliferation by suppressing the cell cycle and inducing apoptosis.

FH535 suppresses cell motility as evidenced in the present study. In addition, FH535 is known to suppress the metastasis of HCC and pancreatic cancer cells $(19,20)$. In this study, the expression levels of matrix metalloproteinase 9 decreased in HLF cells and PLC/PRF/5 cells. The previous reports and our data indicated that FH535 suppresses the motility of cancer cells by decreasing the expression levels of matrix metalloproteinase 9 .

One possible limitation of this study is that the concentration of FH535 was relatively high. FH535 suppressed the proliferation and migration of HCC cells at $50 \mu \mathrm{M}$ with statistical significance. In breast cancer cells, FH535 suppresses proliferation and migration at $1 \mu \mathrm{M}(21)$. A higher concentra-
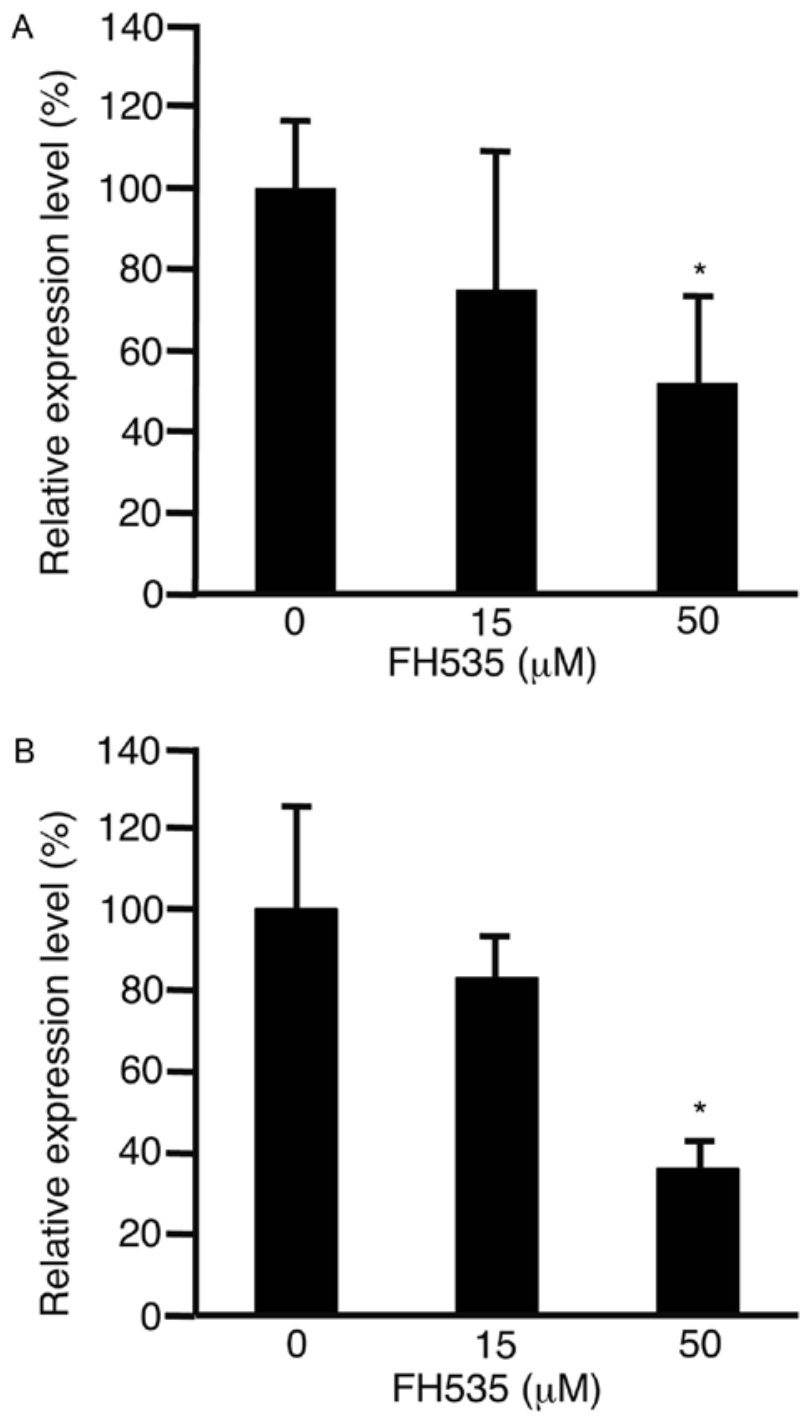

Figure 5. Expression levels of matrix metalloproteinase 9. HLF cells (A) and PLC/PRF/5 cells (B) were cultured with FH535 at 0,15 , or $50 \mu \mathrm{M}$. The RNA was isolated and subjected to real-time quantitative PCR of matrix metalloproteinase 9. Error bar, standard deviation; ${ }^{*} \mathrm{P}<0.05$ as compared with $0 \mu \mathrm{M}$, $\mathrm{n}=3$.

tion might be hazardous to cells, leading to adverse effects. To reduce this risk, using a combination of FH535 and other reagents would be desirable.

FH535 and sorafenib synergistically inhibit the proliferation of Huh-7 cells, another HCC cell line, and cancer stem cells (22). Another application of FH535 is in irradiation therapy (23). In the future, FH535 should be combined with other chemotherapeutic agents or small molecules.

In conclusion, FH535 suppressed cell proliferation by decreasing the expression of cyclin D1 and by inducing apoptosis. In addition, it suppressed cell motility by decreasing the expression of matrix metalloproteinase.

\section{References}

1. Tejeda-Maldonado J, García-Juárez I, Aguirre-Valadez J, González-Aguirre A, Vilatobá-Chapa M, Armengol-Alonso A, Escobar-Penagos F, Torre A, Sánchez-Ávila JF and CarrilloPérez DL: Diagnosis and treatment of hepatocellular carcinoma: An update. World J Hepatol 7: 362-376, 2015. 
2. Lencioni R, Petruzzi P and Crocetti L: Chemoembolization of hepatocellular carcinoma. Semin Intervent Radiol 30: 3-11, 2013.

3. Kim HY and Park JW: Clinical trials of combined molecular targeted therapy and locoregional therapy in hepatocellular carcinoma: Past, present, and future. Liver Cancer 3: 9-17, 2014.

4. Furuse J, Ishii H, Nakachi K, Suzuki E, Shimizu S and Nakajima K: Phase I study of sorafenib in Japanese patients with hepatocellular carcinoma. Cancer Sci 99: 159-165, 2008.

5. Chen C and Wang G: Mechanisms of hepatocellular carcinoma and challenges and opportunities for molecular targeted therapy. World J Hepatol 7: 1964-1970, 2015.

6. Bogaerts E, Heindryckx F, Vandewynckel YP, Van Grunsven LA and Van Vlierberghe $H$ : The roles of transforming growth factor- $\beta$, Wnt, Notch and hypoxia on liver progenitor cells in primary liver tumours (Review). Int J Oncol 44: 1015-1022, 2014.

7. Tanaka SS, Kojima Y, Yamaguchi YL, Nishinakamura R and Tam PP: Impact of WNT signaling on tissue lineage differentiation in the early mouse embryo. Dev Growth Differ 53: 843-856, 2011.

8. MacDonald BT, Tamai K and He X: Wnt/beta-catenin signaling: Components, mechanisms, and diseases. Dev Cell 17: 9-26, 2009.

9. Takahashi-Yanaga F: Activator or inhibitor? GSK-3 as a new drug target. Biochem Pharmacol 86: 191-199, 2013.

10. Jamieson C, Sharma M and Henderson BR: Targeting the $\beta$-catenin nuclear transport pathway in cancer. Semin Cancer Biol 27: 20-29, 2014.

11. Rizvi S and Gores GJ: Molecular profiling and research of therapeutic targets. Dig Dis 33: 586-589, 2015.

12. Monga SP: $\beta$-catenin signaling and roles in liver homeostasis, Injury, and tumorigenesis. Gastroenterology 148: 1294-1310, 2015.

13. Fujimoto T, Tomizawa M and Yokosuka O: SiRNA of frizzled-9 suppresses proliferation and motility of hepatoma cells. Int J Oncol 35: 861-866, 2009.

14. Tomizawa M, Shinozaki F, Motoyoshi Y, Sugiyama T, Yamamoto S, Sueishi M and Yoshida T: Niclosamide suppresses hepatoma cell proliferation via the Wnt pathway. Onco Targets Ther 6: 1685-1693, 2013.
15. Handeli S and Simon JA: A small-molecule inhibitor of Tcf/betacatenin signaling down-regulates PPARgamma and PPARdelta activities. Mol Cancer Ther 7: 521-529, 2008.

16. Davies B and Fried M: The L19 ribosomal protein gene (RPL19): Gene organization, chromosomal mapping, and novel promoter region. Genomics 25: 372-380, 1995.

17. Casimiro MC, Velasco-Velázquez M, Aguirre-Alvarado $\mathrm{C}$ and Pestell RG: Overview of cyclins D1 function in cancer and the CDK inhibitor landscape: Past and present. Expert Opin Investig Drugs 23: 295-304, 2014.

18. Vandooren J, Van den Steen PE and Opdenakker G: Biochemistry and molecular biology of gelatinase B or matrix metalloproteinase-9 (MMP-9): The next decade. Crit Rev Biochem Mol Biol 48: 222-272, 2013.

19. Gedaly R, Galuppo R, Daily MF, Shah M, Maynard E, Chen C, Zhang X, Esser KA, Cohen DA, Evers BM, et al: Targeting the $\mathrm{Wnt} / \beta$-catenin signaling pathway in liver cancer stem cells and hepatocellular carcinoma cell lines with FH535. PLoS One 9: e99272, 2014

20. Wu MY, Liang RR, Chen K, Shen M, Tian YL, Li DM, Duan WM, Gui Q, Gong FR, Lian L, et al: FH535 inhibited metastasis and growth of pancreatic cancer cells. Onco Targets Ther 8: 1651-1670, 2015.

21. Iida J, Dorchak J, Lehman JR, Clancy R, Luo C, Chen Y, Somiari S, Ellsworth RE, Hu H, Mural RJ, et al: FH535 inhibited migration and growth of breast cancer cells. PLoS One 7: e44418, 2012.

22. Galuppo R, Maynard E, Shah M, Daily MF, Chen C, Spear BT and Gedaly R: Synergistic inhibition of HCC and liver cancer stem cell proliferation by targeting RAS/RAF/MAPK and WNT/3-catenin pathways. Anticancer Res 34: 1709-1713, 2014.

23. Su H, Jin X, Zhang X, Zhao L, Lin B, Li L, Fei Z, Shen L, Fang Y, Pan H, et al: FH535 increases the radiosensitivity and reverses epithelial-to-mesenchymal transition of radioresistant esophageal cancer cell line KYSE-150R. J Transl Med 13: 104, 2015. 